\title{
Transfers from prison to hospital under Sections 47 and 48 of the Mental Health Act between 2011 and 2014
}

\begin{abstract}
In England and Wales prisoners with mental disorder of such severity as to warrant inpatient treatment may be transferred to hospital under the Mental Health Act. UK Government guidance recommends that this process should be completed within 14 days; however, evidence suggests that in many cases it can take much longer. This retrospective service evaluation of 64 male prisoners, who were transferred under Section 47 or Section 48, aimed to evaluate transfer durations. The mean time from referral to admission was 76 days. Prisoners with a psychotic disorder were admitted more quickly. Remand prisoners were admitted more quickly than sentenced prisoners. Findings suggest that, in the UK the transfer time of prisoners under Sections 47 and 48 of the Mental Health Act continues to far exceed the 14 day target which raises concern about equivalence of care for prisoners. Our findings support arguments for fundamental amendments to the admissions process.
\end{abstract}




\section{Introduction}

The high prevalence of mental health disorders within the prison population is widely acknowledged (e.g. Fazel \& Danesh, 2002). The largest survey in England and Wales carried out to date found that $58 \%$ of male remand prisoners and $39 \%$ of male sentenced prisoners had a neurotic disorder compared to $12 \%$ of the general population. Ten percent of prisoners displayed symptoms of a psychotic disorder compared to $0.4 \%$ of the general population and $65 \%$ of prisoners had some form of personality disorder (Singleton, Meltzer, \& Gatward, 1998). Prisoners are also recognised as a high risk group for suicide with prison suicide rates far exceeding that of the general population (Fazel, Grann, Kling, \& Hawton, 2011). In addition, aspects of the prison environment (e.g. a lack of meaningful activity, bullying and isolation from social networks) have the potential to contribute to a deterioration in mental health or at least impede recovery (Hassan et al., 2011; Nurse, Woodcock, \& Ormsby, 2003; Leese, Thomas \& Snow, 2006).

In the UK, the National Health Service (NHS) has been responsible for providing prison healthcare since 2006 and inpatient psychiatric treatment for prisoners is commissioned by another part of the NHS. The delivery of prison healthcare is guided by the principle of equivalence that seeks to provide healthcare to prisoners equivalent to that which would be available if they were living in the community. As a result, prisoners now have access to a broader range of health services, including mental health services. Mental Health In-reach Teams (MHITs), which follow the structure of Community Mental Health Teams (CMHTs), were introduced in 2003. The national implementation of Improving Access to Psychological Therapies (IAPT), which offers psychological therapies to people experiencing common mental health problems, has also been introduced in some prisons. Whilst the implementation 
of these services has faced challenges (Brooker \& Gojkovic, 2009; Forrester, MacLennan, Slade, Brown, \& Exworthy, 2014), the impact is deemed to have been positive (Offender Health Research Network [OHRN], 2009).

The concept of equivalent care has undoubtedly guided improvements in the standards of prison healthcare. However, it has been argued that equivalent care does not go far enough and that certain aspects of a prison healthcare system ought to be superior to services which are available in the community (Lines, 2006). This is because the health needs of incarcerated offenders are often much greater than that of the general population and health issues such as HIV and Hepatitis have the potential to spread quickly within a prison environment. Equivalent services therefore would not be sufficient to address these. The suggestion of an alternative framework, to equivalent care, has been put forward by Exworthy et al. (2012) which is available, accessible, acceptable and of good quality. They argue that this is a model of care which would be more adaptable and better suited to the often unique and complex health needs of prisoners.

Whilst the majority of prisoners with mental health needs can be treated in prison, there are circumstances when a prisoner needs to be transferred to a psychiatric hospital for inpatient treatment. This may be the case for prisoners with complex needs or those with acute episodes of severe mental illness who cannot be treated in prison, amongst other reasons because compulsory treatment under the Mental Health Act is not allowed in prison. Official statistics for 2013-14 showed that 862 male prisoners were transferred to a psychiatric hospital for the assessment and treatment of a mental disorder (HSCIC, 2014).

Sections 47 and 48 of the Mental Health Act 1983 (MHA - as amended 2007) provide a legal framework for the transfer of prisoners to hospital for the treatment of a mental disorder. Section 47 applies to the transfer of sentenced prisoners whereas Section 48 is used to 
transfer remanded prisoners. The transfer is granted by the Ministry of Justice (MoJ), on behalf of the Secretary of State if (Subsection 1 of Sections 47 and 48)

“...the Secretary of State is satisfied by the reports of two medical practitioners, of whom at least one is a practitioner approved for the purposes of Section 12 of the said Act, that the said person is suffering from mental disorder within the meaning of the said Act and that the mental disorder is of a nature or degree which makes it appropriate for the patient to be detained in a hospital for medical treatment..."

Section 48 additionally requires that inpatient treatment must be needed urgently.

The Department of Health (DoH) first issued guidance on the procedure of Sections 47 and 48 transfers in 2005 (DoH, 2005). McKenzie \& Sales (2008) evaluated the impact of implementing this guidance on transfer delays in a men's category B prison. They observed a reduction in transfer duration from an average of 77 days pre-implementation to 53 days postimplementation. Elsewhere, three studies have reported on data from 2006; one discovering transfer durations of up to 102 days (Forrester et al. 2009), a second finding that women were transferred more quickly than men with mean transfer times of 15 and 50 days respectively (Roberts et al., 2012) and another reporting that $24 \%$ of transfers had taken longer than 3 months (Wilson et al., 2010).

In his review of mental health and learning disabilities in prison, Lord Bradley recognised that, despite DoH guidance, transfers continued to be taking too long. Bradley (2009) endorsed a 14 day target as a formal recommendation and the Department of Health has subsequently issued good practice guidance on how this could be achieved (DoH, 2011), see Figure 1. In a more recent evaluation, one study has reported average transfer times from a women's closed prison of 51 days (Bartlett et al. 2012). Whilst this is an improvement 
compared to some of the earlier evaluations, this still far exceeds Bradley's 14 day recommendation and jeopardises the principle of equivalence. These delays are of serious concern as they may have a severe impact on mental health including increasing the risk of suicide, attempted suicide and deliberate self-harm. In addition, there is ample evidence for the negative correlation between time of untreated psychosis and outcomes (for a systematic review on this topic see Marshall et al., 2005).

[Figure 1 near here]

A number of factors have been found to have an impact on the transfer duration, including security level of the receiving unit, with transfer times increasing with the level of security (McKenzie \& Sales, 2008; Bartlett et al., 2012), and seriousness of offending, with offenders with less serious offending being transferred more quickly (Bartlett et al., 2012). In addition, one study found considerable differences in transfer times between commissioners, suggesting that some commissioners are more efficient in transferring prisoners than others (Wilson et al., 2010). In an effort to understand more about the barriers to achieving timely transfers, Roberts et al. (2012) conducted interviews with stakeholders involved in the process. A number factors were cited as contributing to delays, including breakdowns in communication, delays in carrying out assessments and disputes over the required level of security. In a report from the Royal College of Psychiatrists (2011) difficulties accessing the prison estate and flow of information within and between organisations were identified as barriers in the transfer process. The majority of psychiatrists who were consulted for this report also stated that having knowledge of the assessing clinician would influence their decision to accept the assessment.

The most recent published evaluations on the transfers of male prisoners are based on data from 2006 (Wilson et al., 2010; Roberts et al., 2012). At the beginning of January 2006 the prison population stood at 74,679 (The Howard League for Penal Reform, 2006). By the start 
of January 2015 this had risen to 84,628 (MoJ, 2015). As well as an increasing prison population, public services in the UK have been challenged by considerable austerity and restructuring following an economic recession. The public prison estate cut spending by $13 \%$ from 2011-2013 (National Offender Management Service [NOMS], 2014) and has seen a drop in its workforce of $29 \%$ over the last 4 years (Prison Reform Trust, 2015). It may be expected therefore that the situation with regards to prison transfers may have deteriorated rather than improved. Our study, using retrospective data on offenders from four prisons in the UK over a $3^{1} / 2$ year period, therefore sought to provide an updated picture of prison transfers for male prisoners and factors that may influence any transfer delays.

Changes beyond mere improved efficiency have been suggested in the literature to reduce delays in these types of admission in the UK. Olomuroti et al. (2009) advocated "prison hospital transfer appeal panels' to arbitrate in contentious referrals and in all cases where delays exceeded a 12-week deadline previously imposed for the transfer of mentally disordered prisoners to hospital. Elsewhere, Wilson et al. (2010) advocated a more thoughtful and discriminating approach to considering whether hospitals always needed to assess referrals given the extensive development of mental health in-reach services and the fact that referrals are made by senior psychiatrists. These authors also suggested that the Ministry of Justice could make more use of its powers to direct prisoners to hospital. However, no such fundamental amendments to admission arrangements have been made.

\section{Method}

\section{Sample}

The sample comprised of all prisoners successfully transferred between 20/11/2011 and 19/05/2015 under Sections 47 or 48 of the Mental Health Act 1983 from four prisons located in the East Midlands \& South Yorkshire region of the United Kingdom. Two prisons were 
local prisons with the primary function of serving the local courts and therefore responsible for detaining remand prisoners as well as some sentenced prisoners. The remaining two prisons were training prisons exclusively for sentenced prisoners. Each prison had an operational capacity broadly in the region of one thousand prisoners.

\section{Data Collection}

Data was extracted from a combination of clinical notes, scanned letters and other documents that were stored on electronic healthcare records (SystemOne, TPP-UK). The following variables were collected:

\section{Prisoner Details}

- Age - This was calculated for each subject as age at the time of admission to hospital

- Diagnosis - Primary diagnosis was extracted from electronic healthcare files. A diagnosis was acknowledged where this was clearly referred to by the psychiatrist in clinical entries, scanned letters (such as hospital referrals) or other documents. Where there was any uncertainty the disorder at the top of any differential diagnosis was extracted.

- Index offence - the majority of prisoners had a psychiatric assessment on their electronic health record with a section describing the index offence. Where this was not the case the index offence was sought via information from clinical entries and communication with Mental Health Inreach Teams. Offences were categorised using the categories described in Bartlett et al. (2012), i.e. Arson, Serious violence, Minor violence, Dishonesty and drugs, Other serious, Other or criminal damage. The current study also included two additional categories of Sexual Offence Violent and Sexual Offence Non-violent. 


\section{Transfer Details}

- Risk of harm - Where an imminent risk to self or others had formed part of the rationale for a referral the prisoner was categorised as 'risk of harm'. Where the prisoner was not considered an imminent risk of harming either himself or others he was categorised as 'no risk of harm'.

- Referred to - Direct to the hospital, to the commissioner or both simultaneously.

- Section Type - Section 47 or Section 48.

- Prison Type - Local or training.

- Receiving hospital - The security level of the receiving hospital was categorised as Psychiatric Intensive Care Unit (PICU), Low, Medium or High. The status of the hospital as within the National Health Service or within the independent sector was recorded.

- Transfer process - Details relating to five time points within the transfer process were identified based on the Good Practice Procedure Guidance issued by the Department of Health (DoH, 2011), see Figure 1.

- $\quad$ Total time to transfer (TTT) - TTT was identified as the number of days between date of a formal referral being made and date of admission to hospital. Whilst the DoH (2011) 14 day transfer clock starts when the need for an inpatient admission is identified, the first time point to have been reliably and consistently recorded in our data was the referral date, hence our decision to use this as the start point of TTT.

\section{Ethical approval}

This was a retrospective service evaluation using routinely recorded data only. The study was assessed as 'service evaluation' by the host Trust's Research \& Development Department and hence did not require ethical approval. Local R\&D approval was granted. 


\section{Statistical analysis}

Mann-Whitney U tests were used to explore differences in transfer times for variables with two categories. For variables with three or more categories a Kruskal-Wallis Analysis of Variance was used to compare transfer times between groups and significant results were followed up with post hoc testing using Mann-Whitney U tests. Following these initial analyses, any variable which found a statistically significant difference in TTT was entered into a logistic regression to consider their ability to predict delays in transfers. For the purpose of this analysis, TTT was transformed into a binary outcome variable which made a distinction between prisoners who were transferred in 30 days or under and those who took 31 days or longer.

All analyses were carried out using the Statistical Package for the Social Sciences (SPSS) version 21. The null hypothesis was rejected when results yielded a $\mathrm{P}$ value of $\leq 0.05$.

\section{Results}

Sixty-four male prisoners were transferred from one of four prisons (which had a combined operational capacity of 4,281) to a total of 26 hospital settings throughout the UK between 20/11/2011 and 19/05/2015. Of these, $44(69 \%)$ were sentenced prisoners transferred under Section 47, the remaining $20(31 \%)$ were remand prisoners transferred under Section 48 of the MHA. The men had a mean age, at the time of admission to hospital, of 33 (range 20-66) years. Twenty-seven men $(42 \%)$ had an index offence which was categorised as Serious Violence; Minor Violence was the next most common offence type (28\%), followed by, Dishonesty and Drugs (14\%), Arson (8\%), Serious Sexual Offence (6\%) and Other (2\%). Whilst categories existed for 'Other or Criminal Damage' and 'Sexual Offence Non-violent', there were no patients fitting either of these categories. The most common psychiatric diagnosis was of a psychotic disorder, with $40(62 \%)$ men having this recorded as their 
primary diagnosis. This was followed by $13(20 \%)$ men with a primary diagnosis of personality disorder, $8(13 \%)$ with an identified mood disorder and $3(5 \%)$ who fell into the category of other diagnoses.

\section{Transfer Duration}

Table 1 shows a breakdown of the transfer process with mean duration, measured in days, between each stage of the transfer process. The mean duration from a referral being made to the patient being admitted to hospital was 75.81 days (median 46). When the duration was measured from the psychiatrists decision to refer (i.e. Time 1 - Time 6), the mean transfer duration increases to 82.47 days (median 53). The stage with the longest duration occurred at Time 3 with a mean of 29 days (median 9), closely followed by Time 2 with a mean of 28 days (median 17).

[Table 1 near here]

Seventeen prisoners (27\%) were transferred within 1 month, of whom 9 (14\%) were transferred within the recommended 14 days. Thirty prisoners (47\%) took between 1 and 3 months to be transferred. Eleven prisoners (17\%) took between 3 and 6 months to be transferred and the remaining $6(9 \%)$ took longer than 6 months to be transferred.

The six prisoners who took longer than 6 months to be transferred were looked at in some further detail in an attempt to identify any common characteristics. Most notably, 5 of the 6 were not considered to be referrals for acute treatment, but were referred because they had specific criminogenic needs that could not be met in prison, e.g. requiring access to a specific modality of psychological therapy or inability to benefit from standard risk reduction interventions owing to mental disorder. The remaining patient, however, was acutely 
psychotic requiring an urgent referral and experienced delays due to conflicting professional judgements about whether they met the requirements for treatment within a specialist unit.

When considering TTT there was one outlier in the data set. Including this outlier in the statistical analyses made no difference to the overall outcome compared to running the analyses without, consequently this individual remained unadjusted in the data set.

Differences in $T T T$ for a number of groups within the sample were considered, full details are presented in Table 2 .

[Table 2 near here]

\section{Type of Prison and TTT}

The median TTT of 41 days (mean 58.37) for prisoners transferred from a local prison was shorter than the 68 days (mean 101.31) for those transferred from a training prison. This difference, just missed statistical significance $U=358.5, \mathrm{z}=-1.85, \mathrm{p}=.06$.

\section{Type of Section and TTT}

TTT for remanded prisoners (Median 33, Mean 39.50), transferred under Section 48, was shorter than it was for sentenced prisoners (Median 63, Mean 92.32), transferred under Section 47. A Mann Whitney test demonstrated that this difference was statistically significant $\mathrm{U}=259, \mathrm{z}=-2.62, \mathrm{p}=.009, \mathrm{r}=-.33$.

\section{Primary Diagnosis and TTT}

$T T T$ was significantly affected by Primary Diagnosis, $\mathrm{H}(3)=7.956, \mathrm{p}=0.047$. Post Hoc testing using Mann-Whitney tests were used to follow up this finding. A Bonferroni correction was applied in interpreting the effects and results are therefore reported to a significance level of .0167 . TTT was significantly shorter for those with a primary diagnosis 
of a Psychotic Disorder compared to those with a Personality Disorder, $U=148.5, z=-2.596$, $\mathrm{p}=.009, \mathrm{r}=-.35 . T T T$ for those with a primary diagnosis of a Mood Disorder (Median 45, Mean 72.43) did not differ significantly from those with a primary diagnosis of Personality Disorder (Median 90, Mean 139.43), $\mathrm{U}=31, \mathrm{z}=-1.34, \mathrm{p}=.179, \mathrm{r}=-.29$ or a Psychotic Disorder (Median 42, Mean 57.40), $\mathrm{U}=136.5, \mathrm{z}=-.105, \mathrm{p}=.917, \mathrm{r}=-.02$.

\section{Offence Type and TTT}

There was no statistically significant difference in $T T T$ between the different offence categories $\mathrm{H}(5)=4.05, \mathrm{p}=0.542$.

Due to small numbers in some offence categories these were collapsed into the two broader categories of Serious Offending and Minor Offending for further comparisons. Those in the Serious Offending group had a longer TTT (Median 53, Mean 83.51) than the Minor Offending group (Median 44, Mean 65.26), but a Mann Whitney U test demonstrated that there was not a statistically significant difference between the groups, $U=435, z=-.88, p=$ .381 .

\section{Level of Required Security and TTT}

Prisoners being transferred to a low secure hospital had the shortest TTT (Median 42, Mean 54.67), transfers to medium secure hospitals took slightly longer (Median 45, Mean 81.33), PICU transfers were marginally longer again (Median 53, Mean 68.60) and transfers to high security hospitals took considerably longer (Median 117, Mean 110.33). There was no statistically significant difference in transfer times between the different levels of security $\mathrm{H}(3)=3.35, \mathrm{p}=.341$ 
Where a referral was made to the hospital only, prisoners had a median transfer duration of 44 days (Mean 76.79). This differed very little to those referred to the commissioners only (Median 45, Mean 55.00). Prisoners who were referred to the hospital and commissioners simultaneously did have a longer TTT (Median 53, Mean 87.82). There was no significant difference in $T T T$ between these three groups $\mathrm{H}(2)=.355, \mathrm{p}=.837$.

\section{Risk of Harm and TTT}

The risk of harm group had a shorter transfer duration (Median $=46$, Mean 75.33) compared to the no risk of harm group (Median 49, Mean 76.63). The difference between the two groups, however, was not statistically significant $\mathrm{U}=478.5, \mathrm{z}=.02, \mathrm{p}=.983$.

\section{Logistic Regression}

The full model containing all predictors was statistically significant, $\chi^{2}=9.58$, $\mathrm{df}=4, \mathrm{p}=$ 0.048. However, as shown in Table 3, in isolation none of the independent variables made a statistically significant contribution to the model.

[Table 3 near here]

\section{Discussion}

This retrospective service evaluation set out to investigate the current state of the transfer of prisoners to psychiatric hospitals under Sections $47 \& 48$ of the Mental Health Act. The study found an average transfer duration of 76 days from a referral being made to a prisoner being admitted to hospital. This is considerably longer than the transfer durations reported in similar evaluations from McKenzie \& Sales (2008), Roberts et al. (2012) and Bartlett et al. (2012) who have reported average transfer durations of 53 days, 50 days and 51 days respectively. Only $14 \%$ of admissions took place within 14 days. Arguably, increases in prisoner numbers coupled with financial austerity in public services mean that the prison 
service and the NHS are under greater strain now than they were in 2006 . This forms the context of our findings.

Bartlett et al. (2012) suggest that the shorter transfer durations seen in their evaluation are likely to be a product of women's services being smaller and fewer in number compared to male services enabling professionals from women's prisons and secure inpatient facilities to foster strong working relationships.

Two stages within the transfer process were notably longer than the others. Firstly, the time between a referral being made to the hospital making their initial assessment (Time 2) took an average of 28 days. This builds on evidence from an earlier evaluation which also reported delays in hospitals conducting their initial assessments (Wilson et al., 2010). It then took, on average, a further 29 days until the second medical recommendation was produced (Time 3). As the medical recommendation is only valid for 56 days it is often the case that the second recommendation is not provided until an available bed space has been confirmed. Much of the delay at Time 3 then is not a case of waiting for the recommendation but can be attributed to the receiving hospital coming to a decision on suitability for admission and waiting for a bed to become vacant. When these two stages are considered within the context of equivalence of care, the process is clearly falling short, delaying access to treatment with potentially adverse consequences for the prisoner.

Psychiatrists commonly report barriers in accessing the prison estate, including restricted visiting hours and difficulties with notice required prior to visits (Royal College of Psychiatrists, 2011). In sum, it is likely that the greatest delays are caused by inpatient providers not assessing referrals in a timely fashion, which in part may be caused by prison procedures, and being able to agree admission. 
We found that only 18 prisoners were admitted under Sections 47 and 48 per annum from the four prisons collectively. This suggests that delay is not being caused by large numbers being admitted to hospital, although we acknowledge that a significant number of other prisoners will have been diverted from the court under other sections of the MHA.

Psychiatric diagnosis and Section Type were the only two factors for which TTT differed significantly. Those with a primary diagnosis of psychosis were found to have a shorter transfer duration compared to those with a primary diagnosis of a personality disorder. A likely explanation lies within the differing treatment needs of the two groups. Prisoners with psychosis are often referred to hospital during an acute episode of their illness, particularly if they are refusing medication, food or fluids. This is likely to result in a rapid transfer to a hospital for acute compulsory treatment under the Mental Health Act. Treatment options for those with a personality disorder are predominantly psychological interventions, often unavailable in prison, requiring motivation and a desire to change problematic behaviours. Referrals for this type of treatment could be considered less urgent and may also appear less clear to commissioners whether treatment should be provided in hospital or prison. In addition some hospitals do not accept patients with a diagnosis of Personality Disorder.

Remanded prisoners had significantly shorter transfer times than sentenced prisoners. Whilst the evaluation did not measure symptom severity, it has been shown that remand prisoners have higher rates of mental disorder and are at a greater risk of self-harm and suicide than sentenced prisoners (Humber, Hayes, Senior, Fahy, \& Shaw, 2011). Being remanded in prison is thought to be particularly stressful due to the uncertainty of a pending trial and limited opportunities to partake in meaningful activity, such as paid work (Nurse et al., 2003). We also note that all referrals of remand prisoners are for urgent treatment so would expect them to be dealt with more quickly. 
The current study did not find support for a significant relationship between required level of security and transfer duration. This is in contrast to previous studies which found that transfers to medium secure settings took significantly longer than transfers to PICU and general psychiatric inpatient units (McKenzie \& Sales, 2008; Bartlett et al., 2012). Our finding is likely to be limited by an under-representation of prisoners who were transferred to high security hospitals. However, as they stand, the results do suggest that transfer delays are not greatly affected by the hospital security level or the nature of the index offence.

Since an overlap between the variables of offence type and hospital security level is likely to exist it is perhaps not surprising that there was no evidence of a difference in TTT by offence type. Again this is in contrast to what was reported by Bartlett et al. (2012) who found that serious offenders took longer to be transferred than minor offenders. The fact that there was no significant difference between offence categories, in our view, makes sense. Whilst the index offence is relevant in considering level of security required the judgement of suitability for admission should be based on the mental health needs of the individual and would therefore not be expected to have a significant impact on transfer duration.

Whilst transfers from the training prisons took longer than from the local prisons, this difference did just fail to reach a level of statistical significance. It is likely that this outcome is closely related to the findings for sentence and remand prisoners since training prisons only accommodate sentenced prisoners and local prisons hold a mix of remand and sentenced prisoners.

There was very little difference in the referral times for those who presented a risk to themselves and/or others and those who did not. This is somewhat surprising as it could be expected that those presenting with some level of risk would be treated as more urgent referrals. This finding is potentially offset by the large proportion of individuals identified as 
posing a risk who were also diagnosed with a Personality Disorder. As discussed previously the Personality Disorder group faced the longest delays out of all the diagnosis categories. Furthermore, we did not consider the severity of the presenting risk, it would be expected that those presenting with a severe and imminent risk of harm to be transferred more quickly.

A logistic regression did not find diagnosis or type of transfer to be significant predictors of transfer duration. Whilst significant differences in TTT did occur between these variables, this finding suggests that these variables are not sufficient for predicting transfer delays.

Our findings support the proposal made by Olumoroti et al. (2009) for 'prison hospital transfer appeal panels' to arbitrate in contentious referrals and delayed transfers. More than a quarter of referrals in this study were delayed beyond the 12-week limit advocated by these authors. We assert it to be a plain fact that access to inpatient treatment should not take this long.

In our view, our data also supports the views advanced by Wilson et al. (2010) that there should be greater flexibility in arranging these admissions so that at least some are accepted without further assessment by the inpatient unit. We appreciate that secure psychiatric inpatient services are an expensive provision and that such units have a responsibility to protect these through gatekeeping. However, we question whether scrutiny of referrals needs to be done by interview in uncontentious cases. Furthermore, this would not appear to be equivalent care to that provided to those in the community, e.g. few admissions to nonsecure, general adult units would be assessed in advance by their prospective Responsible Clinician.

A shortcoming of the current setup relates to how referrals made by senior consultant psychiatrists in the prisons, with a longitudinal view, can be blocked by a hospital representative who has carried out a comparatively brief gatekeeping assessment. We propose 
that secure hospitals provide Offender Health commissioners with the option of purchasing a small number of beds where the admission rights would sit with the referring prison psychiatrist. These beds would be available to prison psychiatrists for the most urgent of transfers, circumventing the need for hospital clinicians to gain access to the prison estate, thus reducing delays in admission. Whilst it is foreseeable that such an initiative could create some confusion around the issue of the responsible commissioner, it would clearly prioritise patient need.

Evidence suggests that services can successfully reduce transfer delays when they carefully design and implement protocols dedicated to doing so. We encourage services to actively consider initiatives, including approaches evaluated by Forrester et al. (2013) which made use of clinicians who were tasked with facilitating the transfer process.

Finally, we would welcome further debate about extending some compulsory treatment powers to prisons (perhaps by establishment of units with designated status as hospitals with a prison's secure area). Although the nature of treatment eventually received in hospital was beyond the scope of this service evaluation, we suspect that for many non-compliant, psychotic patients, the most important intervention is re-establishment of antipsychotic medication. Potential benefits of being able to do this in prison would be shorter duration of untreated psychosis (with commensurate improved prognosis) and significant saving to the health budget from reduced admissions. One conclusion from our findings about the source of greatest delay in the admissions process might be that more resources should be allocated to inpatient providers. However, we suggest that expansion of treatment powers within prison could result in some prisoners receiving effective treatment more quickly and cost effectively without the need for hospital admission.

The need to transfer out of prison could be reduced with the provision of beds on psychiatric prison wards, as is the case throughout large parts of Europe (Salize, Dreßing \& Kief, 2007). 
The issue with prison hospitals however, will always be the non-therapeutic environment and conflicting priorities between security and healthcare.

\section{Limitations}

A key limitation of this evaluation is the small size of some of the groups which have been used for making comparisons. Where possible, smaller groups have been incorporated into larger ones to allow for a more meaningful statistical analysis, this has compromised our ability to draw conclusions for the smaller groups.

Comparability between this and earlier studies may be limited to some extent by the fact that variations exist in the methods of measuring total transfer duration. Where some studies have measured transfer duration from the identification of a need to refer (Bartlett et al., 2012; Roberts, 2012), the current study and one other (Forrester et al., 2009) have measured the transfer duration from the point at which a referral was made.

Whilst transfers were made to units nationwide, the current study is limited by the fact that the majority were to units in the East Midlands. Whilst we are confident that delays are an issue throughout the UK, a larger evaluation incorporating a more balanced representation of transfers nationwide would be helpful and may identify variation in efficiency across the country.

The current study did not differentiate between levels of urgency within the two section groups (Section 47 and Section 48), although within the statute all Section 48 transfers have to be for urgent treatment. It is likely that urgency of referral is reflected in the transfer duration. It would be useful for future studies to categorise levels of referral urgency.

Finally, our study focussed on a specific element of the DoH (2011) guidance, i.e. the transfer process, and did not consider broader elements within the document e.g. guidance on 
identifying the relevant commissioner. It would be of interest to establish how much of the DoH guidance is being followed and the subsequent impact on transfer duration.

\section{Conclusion}

Transfer of prisoners under Section 47 and Section 48 of the Mental Health Act continue to greatly exceed the 14 day transfer target which was set out 6 years ago. Equivalence of care recognises that prisoners should have access to the same standard of treatment that they would receive if they were living in the community; the current evaluation has demonstrated that this is not being achieved. Prisoners with severe mental health problems represent some of the most vulnerable people in our society and they are being unfairly disadvantaged by not having timely access hospital treatment. In the UK, transfer of many severely mentally disordered prisoners is very prolonged and appears to be getting more prolonged.

Public sector prisons reduced spending by $£ 263 \mathrm{~m}$ (13\%) from 2011-13, with a further $£ 75 \mathrm{~m}$ of savings planned for 2014/15 (NOMS, 2014). Therefore, transfer delays are likely to be a sign of the Prison Service and National Health Service struggling under the strain of financial austerity and full prisons.

The greatest proportion of the transfer delay can be attributed to responsibilities that lie with the hospitals, including organising a gatekeeping assessment, deciding upon acceptance or rejection of the referral and identifying an available bed space. In order to have the greatest impact on reducing transfer durations these components require attention.

\section{References}

Bartlett, A., Somers, N., Reeves, C., \& White, S. (2012). Women prisoners: an analysis of the process of hospital transfers. The Journal of Forensic Psychiatry and Psychology, 23 (4): 538-53. DOI: 10.1080/14789949.2012.706628

Bradley, K. (2009). The Bradley report: A review of people with mental health problems and learning disabilities in the criminal justice system. Retrieved from http://www.centreformentalhealth.org.uk/pdfs/Bradley_report_2009.pdf 
Brooker, C., \& Gojkovic, D. (2009). The second national survey of mental health in-reach services in prisons. The Journal of Forensic Psychiatry \& Psychology, 20 (s1), s1128.

Department of Health. (2005). Procedure for the Transfer of Prisoners to and from Hospital under Sections 47 and 48 of the Mental Health Act 1983. Retrieved from http://webarchive.nationalarchives.gov.uk/20130107105354/http://www.dh.gov.uk/pr od_consum_dh/groups/dh_digitalassets/@dh/@en/documents/digitalasset/dh_412363 1.pdf

Department of Health. (2011). Good Practice Procedure Guide. The transfer and remission of adult prisoners under s47 and s48 of the Mental Health Act. Retrieved from https://www.gov.uk/government/publications/the-transfer-and-remission-of-adultprisoners-under-s47-and-s48-of-the-mental-health-act

Fazel, S., \& Danesh, J. (2002). Serious mental disorder in 23000 prisoners: a systematic review of 62 surveys. The Lancet, 359, 545-50.

Fazel, S., Grann, M., Kling, B., \& Hawton, K. (2011) Prison suicide in 12 countries: an ecological study of 861 suicides during 2003-2007. Social Psychiatry and Psychiatric Epidemiology, 46, 191-5.

Forrester, A., Henderson, C., Wilson, S., Cumming, I., Spyrou, M., \& Parrott, J. (2009). A suitable waiting room? Hospital transfer outcomes and delays from two London prisons. Psychiatric Bulletin, 33, 409-12.

Forrester, A., Exworthy, T., Chao, O., Slade, K., \& Parrott, J. (2013). Influencing the care pathway for prisoners with acute mental illness. Criminal Behaviour and Mental Health, 23, 217-26

Forrester, A., MacLennan, F., Slade, K., Brown, P., \& Exworthy, T. (2014). Improving access to psychological therapies in prisons. Criminal Behaviour and Mental Health, 24, 163-68.

Hassan, L., Birmingham, L., Harty, M., Jarrett, M., Jones, P., King, ... Shaw, J. (2011). Prospective cohort study of mental health during imprisonment. The British Journal of Psychiatry, 198(1), 37-42.

Health \& Social Care Information Centre (HSCIC). (2014). Inpatients formally detained in hospitals under the Mental Health Act 1983, and patients subject to supervised community treatment: Annual report, England, 2013/14. Retrieved from http://www.hscic.gov.uk/catalogue/PUB15812/inp-det-m-h-a-1983-sup-com-eng-1314-rep.pdf

Humber, N., Hayes, A., Senior, J., Fahy, T., Shaw, J. (2011). Identifying, monitoring and managing prisoners at risk of self-harm/suicide in England and Wales. The Journal of Forensic Psychiatry \& Psychology, 22(1), 22-51.

Leese, M., Thomas, S., Snow, L. (2006). An ecological study of factors associated with rates of self-inflicted death in prisons in England and Wales. International Journal of Law and Psychiatry, 29(5), 355-60

Marshall, M., Lewis, S., Lockwood, A., Drake, R., Jones, P., Croudace, T. (2005). Association Between Duration of Untreated Psychosis and Outcome in Cohorts of First-Episode Patients: A Systematic Review. Archives of General Psychiatry, 62(9), 975-83.

McKenzie, N., \& Sales, B. (2008). New procedures to cut delays in transfer for mentally ill prisoners to hospital. Psychiatric Bulletin, 32(1), 20-22

Ministry of Justice (MoJ). (2015). Prison population figures: 2015. Retrieved from https://www.gov.uk/government/statistics/prison-population-figures-2015

National Offender Management Service (NOMS). (2014). Business Plan 2014-2015, London: NOMS. Retrieved from 
https://www.gov.uk/government/uploads/system/uploads/attachment_data/file/30277 6/NOMS_Business_Plan_201415.pdf

Nurse, J., Woodcock, P., Ormsby, J. (2003). Influence of environmental factors on mental health within prisons: focus group study. British Medical Journal, 27, 480-85. DOI: http://dx.doi.org/10.1136/bmj.327.7413.480

Offender Health Research Network (OHRN). (2009). A national evaluation of prison mental health in-reach services: a report to the National Institute of Health Research. retrieved from http://www.ohrn.nhs.uk/resource/Research/Inreach.pdf

Olumoroti, O., Forrester, A., Wilson, S., \& Dewhurst, J. (2009). Mentally ill prisoners in need of urgent hospital transfer: appeal panels should resolve disputes to reduce delays. The Journal of Forensic Psychiatry and Psychology, 20(S1) S5-S10.

Prison Reform Trust. (2015). Prison: the facts, London: Prison Reform Trust. Retrieved from http://www.prisonreformtrust.org.uk/Portals/0/Documents/Prison\%20the\%20facts $\% 2$ 0May\%202015.pdf

Roberts, A. J., Senior, J., Hayes, A. J., Stevenson, C., \& Shaw, J. (2012). An independent evaluation of the Department of Health's procedure for the transfer of prisoners to hospital under the Mental Health Act 1983. The Journal of Forensic Psychiatry \& Psychology, 23(2), 217-36.

Royal College of Psychiatrists. (2011). Prison transfers: A survey from the Royal College of Psychiatrists. London.

Salize, H., Dreßing, H., \& Kief, C. (2007). Mentally disordered persons in European prison systems - Needs, programmes and outcome (EUPRIS). European Commission.

Singleton, N., Meltzer, H., \& Gatward, R. (1998). Psychiatric morbidity among prisoners in England and Wales. London: ONS.

The Howard League for Penal Reform. (2006). Prison population: June 2006. Retrieved from http://www.howardleague.org/prison-population-jan2006/

Wilson, S., Chiu, K., Parrott, J., \& Forrester, A. (2010). Postcode lottery? Hospital transfers from one London prison and responsible catchment area. The Psychiatrist, 3, 140-42. 